\section{A) Check for updates}

Cite this: Org. Chem. Front., 2017, 4, 1051

\title{
(1S)-(-)-N-Trifluoromethylthio-2,10- camphorsultam and its derivatives: easily available, optically pure reagents for asymmetric trifluoromethylthiolation $\dagger$
}

\author{
He Zhang, Xuebing Leng, Xiaolong Wan and Qilong Shen*
}

Received 16th January 2017,

Accepted 9th February 2017

DOI: $10.1039 / \mathrm{c} 7 \mathrm{qo0} 00042 \mathrm{a}$

rsc.li/frontiers-organic

\begin{abstract}
A family of easily scalable, shelf-stable, optically pure reagents (1S)-(-)-N-trifluoromethylthio-2,10-camphorsultam 1a-c was successfully developed. In particular, compound 1c was shown to be an efficient reagent that is capable of transferring chirality to other prochiral nucleophiles such as $\beta$-ketoesters, oxindoles and benzofuranones with good to excellent enantioselectivities.
\end{abstract}

\section{Introduction}

Over the past two decades, fluorine and its magic "fluorine effect" in the discovery of new drug molecules have been well recognized in the fields of the pharmaceutical and agrochemical industries. ${ }^{1}$ Consequently, strategic incorporation of a fluorine atom or a fluoroalkyl group into therapeutic or agrochemical agents has become a routine tool to manipulate the target molecule's physical, chemical and biological properties including conformation, $\mathrm{p} K_{\mathrm{a}}$, intrinsic potency, metabolic pathways, and pharmacokinetic properties. In particular, recently, the trifluoromethylthio group $\left(-\mathrm{SCF}_{3}\right)$ has gained intense interest, mainly due to its high lipophilicity (Hansch's hydrophobicity parameter $\pi=1.44$ ) that may improve the molecule's trans-membrane permeability. ${ }^{2}$ Not surprisingly, new reagents and new methods that are able to introduce the trifluoromethylthio group effectively are in high demand. ${ }^{3}$ As a matter of fact, in the last five years, a number of electrophilic trifluoromethylthiolating reagents, ${ }^{4}$ as well many transition metal-catalyzed trifluoromethylthiolation reactions ${ }^{5,6}$ emerged, that now allow for the construction of the $\mathrm{C}\left(\mathrm{sp}^{2}\right)-\mathrm{SCF}_{3}, \mathrm{C}\left(\mathrm{sp}^{3}\right)-$ $\mathrm{SCF}_{3}$ or $\mathrm{C}(\mathrm{sp})-\mathrm{SCF}_{3}$ bonds efficiently.

Despite these impressive advances in developing the methods for the formation of $\mathrm{C}-\mathrm{SCF}_{3}$ bonds, very few methods that could generate optically active compounds with a stereogenic carbon center bearing a trifluoromethylthio group have

Key Laboratory of Organofluorine Chemistry, Shanghai Institute of Organic

Chemistry, 345 Lingling Lu, Shanghai, 200032, China. E-mail: shen@mail.sioc.ac.cn $\dagger$ Electronic supplementary information (ESI) available: Synthesis, analytical data, computational details, NMR data of compounds 1a-f, 3a-n, 4a-p, 5a-h and X-ray crystallography data of 1a-c, $\mathbf{4 i}$ and 5c. CCDC 1527557-1527562. For ESI and crystallographic data in CIF or other electronic format see DOI: 10.1039/ c7qo00042a been reported. ${ }^{7}$ In 2013, Shen's and Rueping's groups simultaneously reported the first highly enantioselective cinchona alkaloid-catalyzed asymmetric trifluoromethylthiolation of cyclic $\beta$-ketoesters with trifluoromethanesulfenate ${ }^{7 a}$ or $N$-trifluoromethylphthalimide ${ }^{7 b}$ as the electrophilic $\mathrm{SCF}_{3}$ reagent, respectively. Later on, the asymmetric reactions were successfully extended to trifluoromethylthiolation of oxindoles with excellent enantioselectivity. ${ }^{7 e} f$ Likewise, Liu and Tan discovered that the organocatalytic asymmetric trifluoromethylthiolation of oxindoles can be achieved when an in situ formed electrophilic trifluoromethylthio species generated from trichloroisocyanuric acid (TCCA) and $\mathrm{AgSCF}_{3} .{ }^{7 d}$ Very recently, Zhao's group reported the first chiral sulphide-catalyzed asymmetric trifluoromethylthiolating lactonization of alkenes with $N$-trifluoromethylthiodibenzenesulfonimide. ${ }^{7 g}$ On the other hand, Gade and co-workers reported the first copper-catalyzed asymmetric trifluoromethylthiolation of cyclic $\beta$-ketoesters using the trifluoromethanesulfenate reagent. ${ }^{7 c}$ Nevertheless, new and highly enantioselective methods for the construction of a stereogenic carbon center bearing a trifluoromethylthio group are still urgently needed.

Chirality transfer from a chiral reagent to a prochiral substrate to give the product in high enantiomeric excess represents a general and efficient method for the production of optically active compounds. ${ }^{8}$ In this respect, the design and exploration of optically pure electrophilic trifluoromethylthiolating reagents for asymmetric trifluoromethylthiolation offers a simple and straightforward strategy for the formation of a stereogenic carbon center bearing a trifluoromethylthio group, which would complement the previously reported asymmetric trifluoromethylthiolation methods. Herein, we report the design and synthesis of (1S)-(-)- $N$-trifluoromethylthio-2,10camphorsultam $^{9}$ and its derivatives, a family of optically pure reagents that can efficiently transfer their chirality to prochiral 
substrates such as $\beta$-ketoesters, oxindoles and benzofuran$2(3 H)$-ones with good to excellent enantioselectivities.

\section{Results and discussion}

\section{Preparation of (1S)-(-)- $N$-trifluoromethylthio-2,10- camphorsultam and $\mathrm{N}$-trifluoromethylthio-oxazolidin-2-one and their derivatives}

$(1 S)-(-)-N$-Trifluoromethylthio-2,10-camphorsultam 1a could be easily synthesized via a two-step procedure, as shown in Fig. 1. Reaction of commercially available $(1 S)-(-)-2,10$-camphorsultam with tert-butyl hypochlorite in methanol at room temperature for $45 \mathrm{~min}$ yielded $(1 S)-(-)-N$-chloro-2,10-camphorsultam in quantitative yield. Without further purification, the in situ generated (1S)-(-)- $N$-chloro-2,10-camphorsultam was then further treated with $\mathrm{AgSCF}_{3}$ in $\mathrm{CH}_{3} \mathrm{CN}$ at room temperature for $1 \mathrm{~h}$ to give $(1 S)-(-)$ - $N$-trifluoromethylthio-2,10-camphorsultam 1a in $68 \%$ yield. The reaction can be easily scaled up to a quantity of $4.7 \mathrm{~g}$ without erosion of the yield. Likewise, two analogous compounds $\mathbf{1 b}$ and $\mathbf{1 c}$ were prepared in $73 \%$ and $79 \%$ yield, respectively. In addition, compounds 1d-f derived from oxazolidin-2-one were synthesized by the same method in $71-82 \%$ yields, as shown in Fig. 1. Compounds 1a-f were fully characterized by ${ }^{1} \mathrm{H},{ }^{13} \mathrm{C}$, and ${ }^{19} \mathrm{~F}$ NMR spectroscopy. The structures of compounds $\mathbf{1 a - c}$ were further unambiguously confirmed by X-ray analysis of their single crystals (Fig. 2).

\section{Asymmetric trifluoromethylthiolation of $\beta$-ketoesters with reagent 1c}

To probe whether compounds 1a-f can efficiently transfer their chirality to other substrates, we first studied the reactions of $\beta$-ketoesters with compounds 1a-f. The reaction of $\beta$-ketoester 2a derived indanone with compound 1a was chosen initially as a model reaction to optimize the reaction parameters. A quick screening of the base disclosed that the
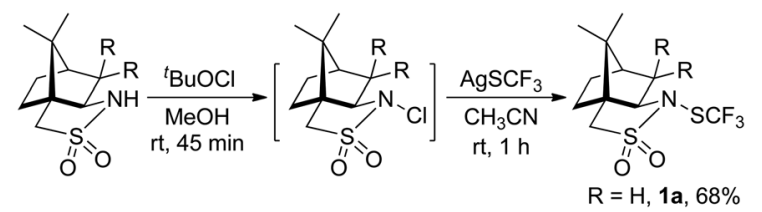
Cl, $\mathbf{1 b}, 73 \%$ OMe, 1c, $79 \%$

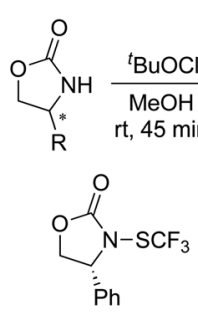

1d, $76 \%$

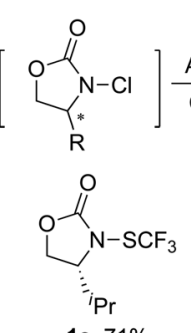

$1 \mathrm{e}, 71 \%$
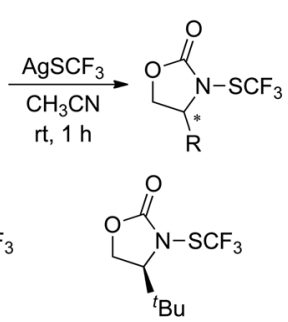

1f, $82 \%$
Fig. 1 Preparation of (1S)-(-)- $N$-trifluoromethylthio-2,10-camphorsultam and $\mathrm{N}$-trifluoromethylthio-oxazolidin-2-one and their derivatives.

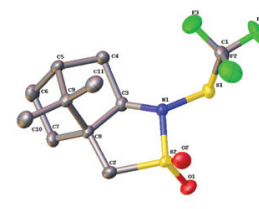

$1 \mathbf{a}$

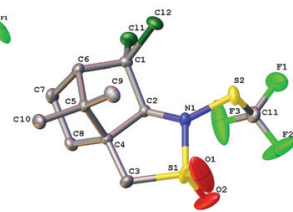

$1 \mathrm{~b}$

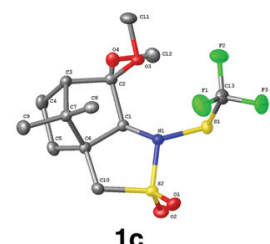

$1 \mathrm{c}$
Fig. 2 ORTEP diagrams of compounds $1 \mathrm{a}-\mathrm{c}$.

desired trifluoromethylthio- $\beta$-ketoester $\mathbf{3 a}$ was generated in higher yield when the reaction was conducted in THF using $\mathrm{K}_{2} \mathrm{CO}_{3}$ as the base than those using $\mathrm{Cs}_{2} \mathrm{CO}_{3}, \mathrm{Li}_{2} \mathrm{CO}_{3}, \mathrm{~K}_{3} \mathrm{PO}_{4}$ or DMAP as the base (Scheme 1, entries 1-5). Next, the effect of the solvents was studied. Reactions in THF occurred much faster than those in $\mathrm{CH}_{2} \mathrm{Cl}_{2}, \mathrm{Et}_{2} \mathrm{O}$ or toluene (Scheme 1, entries 6-9). For example, reaction of $\beta$-ketoester 2 a with compound 1a occurred in $78 \%$ yield with $77 \%$ ee after $12 \mathrm{~h}$ at $-20{ }^{\circ} \mathrm{C}$ while reactions in $\mathrm{CH}_{2} \mathrm{Cl}_{2}, \mathrm{Et}_{2} \mathrm{O}$ or toluene occurred in less than $10 \%$ conversion under otherwise identical conditions. Under the current reaction conditions $\left(\mathrm{K}_{2} \mathrm{CO}_{3}\right.$ as the base, THF as the solvent, $-20^{\circ} \mathrm{C}, 12 \mathrm{~h}$ ), we compared the reactivity of compounds 1a-f. Interestingly, reactions of compounds 1a-c derived from (1S)-(-)-camphorsultam were much faster and with higher enantioselectivity than reactions of compounds 1d-f derived from oxazolidin-2-one (Scheme 1, entries 7, 10-14). In addition, compound 1c with two methoxy groups reacted faster and with higher enantioselectivity than its analogs 1a-b (Scheme 1, entries 7, 10 and 11). With these promising results in mind, we further optimized the reaction

\begin{tabular}{|c|c|c|c|c|c|c|c|}
\hline \multicolumn{2}{|c|}{$2 a$} & \multicolumn{3}{|c|}{$1 a-f$} & \multicolumn{3}{|c|}{$3 a$} \\
\hline entry & agent & base & solvent & $\begin{array}{l}\text { temp } \\
\left({ }^{\circ} \mathrm{C}\right)\end{array}$ & $\begin{array}{l}\text { time } \\
\text { (h) }\end{array}$ & $\begin{array}{c}\text { yield } \\
(\%)\end{array}$ & $\begin{array}{c}\text { ee } \\
(\%)\end{array}$ \\
\hline 1 & $1 a$ & $\mathrm{~K}_{2} \mathrm{CO}_{3}$ & THF & $\mathrm{rt}$ & 12 & 82 & 34 \\
\hline 2 & $1 a$ & $\mathrm{Cs}_{2} \mathrm{CO}_{3}$ & THF & $\mathrm{rt}$ & 12 & 31 & 21 \\
\hline 3 & $1 a$ & $\mathrm{Li}_{2} \mathrm{CO}_{3}$ & THF & $\mathrm{rt}$ & 12 & - & - \\
\hline 4 & $1 a$ & $\mathrm{~K}_{3} \mathrm{PO}_{4}$ & THF & $\mathrm{rt}$ & 12 & 73 & 26 \\
\hline 5 & $1 a$ & DMAP & THF & $\mathrm{rt}$ & 12 & 2 & - \\
\hline 6 & $1 a$ & $\mathrm{~K}_{2} \mathrm{CO}_{3}$ & $\mathrm{CH}_{2} \mathrm{Cl}_{2}$ & -20 & 12 & 6 & - \\
\hline 7 & $1 a$ & $\mathrm{~K}_{2} \mathrm{CO}_{3}$ & THF & -20 & 12 & 78 & 77 \\
\hline 8 & $1 a$ & $\mathrm{~K}_{2} \mathrm{CO}_{3}$ & $\mathrm{Et}_{2} \mathrm{O}$ & -20 & 12 & 4 & - \\
\hline 9 & $1 a$ & $\mathrm{~K}_{2} \mathrm{CO}_{3}$ & toluene & -20 & 12 & 7 & - \\
\hline 10 & $1 b$ & $\mathrm{~K}_{2} \mathrm{CO}_{3}$ & THF & -20 & 12 & 63 & 57 \\
\hline 11 & 1c & $\mathrm{K}_{2} \mathrm{CO}_{3}$ & THF & -20 & 12 & 83 & 83 \\
\hline 12 & $1 d$ & $\mathrm{~K}_{2} \mathrm{CO}_{3}$ & THF & -20 & 52 & 62 & 17 \\
\hline 13 & $1 \mathrm{e}$ & $\mathrm{K}_{2} \mathrm{CO}_{3}$ & THF & -20 & 52 & 34 & 43 \\
\hline 14 & $1 f$ & $\mathrm{~K}_{2} \mathrm{CO}_{3}$ & THF & -20 & 52 & 40 & 36 \\
\hline 15 & 1c & $\mathrm{K}_{2} \mathrm{CO}_{3}$ & THF & -40 & 12 & 61 & 89 \\
\hline 16 & 1c & $\mathrm{K}_{2} \mathrm{CO}_{3}$ & THF & -40 & 24 & 53 & $89^{d}$ \\
\hline 17 & 1c & $\mathrm{K}_{2} \mathrm{CO}_{3}$ & THF & -40 & 48 & 73 & $88^{d}$ \\
\hline 18 & $1 c$ & $\mathrm{~K}_{2} \mathrm{CO}_{3}$ & THF & -40 & 72 & 89 & $88^{d}$ \\
\hline
\end{tabular}

Scheme 1 Optimization of the conditions for the reactions of $\beta$-ketoester 2a with compounds $1 \mathrm{a}-\mathrm{f}^{a, b, c}{ }^{a}$ Reaction conditions: $\beta$-ketoester 2a $(0.050 \mathrm{mmol})$, reagents $1 \mathrm{a}-\mathrm{f}(0.055 \mathrm{mmol})$, base $(1.1 \mathrm{mmol})$ in $0.5 \mathrm{~mL}$ of solvent; ${ }^{b}$ yields were determined by ${ }^{19} \mathrm{~F}$ NMR spectroscopy in the presence of trifluoromethylbenzene as the internal standard; ${ }^{c}$ the ee values were determined by HPLC analysis on a chiral stationary phase. ${ }^{d} 0.1$ equivalent of $\mathrm{K}_{2} \mathrm{CO}_{3}$ was used. 
conditions using compound $\mathbf{1 c}$ as the electrophilic trifluoromethylthiolating reagent. It was found that reactions using 0.1 equivalent of $\mathrm{K}_{2} \mathrm{CO}_{3}$ as the base worked equally efficient, while reactions conducted at $-40{ }^{\circ} \mathrm{C}$ occurred slowly but with higher enantioselectivity (Scheme 1, entry 16). Finally, full conversion of the substrate was achieved by elongating the reaction time to $72 \mathrm{~h}$ (Scheme 1, entry 18).

\section{Scope of the asymmetric trifluoromethylthiolation of $\beta$-ketoesters with reagent 1c}

With the optimum reaction conditions in hand, the stage was set to explore the scope and the limitation of the asymmetric trifluoromethylthiolation reactions. A variety of $\beta$-ketoesters 2a-o derived from indanone or tetralone were subjected to the optimized conditions and the results are summarized in Scheme 2. In general, reactions of six-membered ring $\beta$-ketoesters occurred with higher enantioselectivities than those of five-membered ring $\beta$-ketoesters. Reactions of sixmembered ring $\beta$-ketoesters typically generated the desired trifluoromethylthiolated compounds in $94-98 \%$ ee while reactions of five-membered ring $\beta$-ketoesters gave the desired products in $79-92 \%$ ee. In addition, reactions of less nucleophilic $\beta$-ketoesters with an electron-withdrawing group such as fluo-

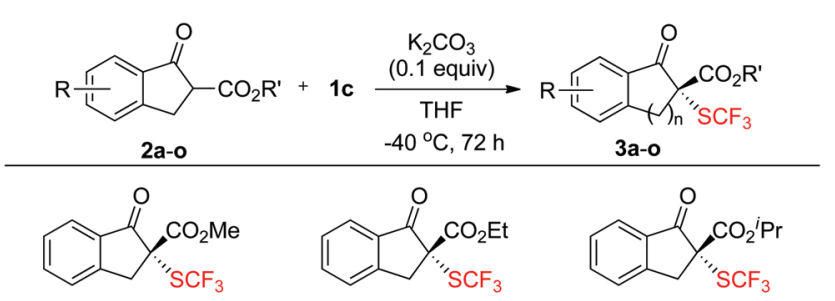

3a, $94 \%, 88 \%$ ee

3b, $90 \%, 90 \%$ ee

$3 c, 95 \%, 89 \%$ ee
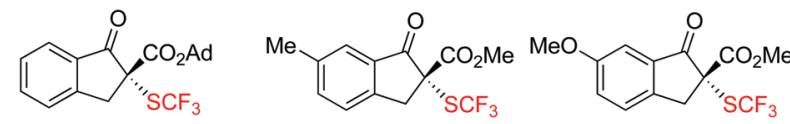

3d, $93 \%, 92 \%$ ee

3e, $91 \%, 91 \%$ ee

3f, $77 \%, 91 \%$ ee
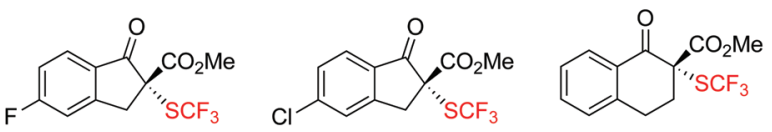

3 g, $81 \%, 86 \% \mathrm{ee}^{\mathrm{c}}$

3h, $72 \%, 80 \% \mathrm{ee}^{c}$

3i, $82 \%, 98 \%$ ee<smiles>COc1ccc2c(c1)C(=O)[C@@](C(C)=O)(C(C)(F)F)CC2</smiles><smiles>COc1ccc2c(c1)CCC(C(C)(F)F)(C(C)(F)F)C2=O</smiles><smiles>COc1cccc2c1CC[C@](C(C)=O)(C(F)(F)F)C2=O</smiles>

3j, $87 \%, 95 \%$ ee

3k, $92 \%, 94 \%$ ee

3I,

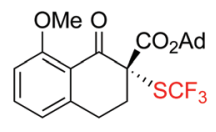

3m, $90 \%$, 98\% ee

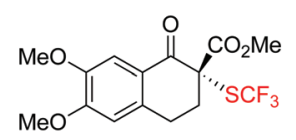

3 n, $95 \%, 95 \%$ ee

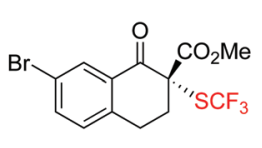

3o, $84 \%, 96 \% \mathrm{ee}^{c}$
Scheme 2 Scope of the reactions of $\beta$-ketoesters $2 \mathrm{a}-\mathrm{n}$ with compound 1c. ${ }^{a, b}{ }^{a}$ Reaction conditions: $\beta$-ketoester $2 \mathrm{a}(0.50 \mathrm{mmol})$, reagent $1 \mathrm{c}$ $(0.55 \mathrm{mmol}), \mathrm{K}_{2} \mathrm{CO}_{3}(0.050 \mathrm{mmol})$ in $2.5 \mathrm{~mL}$ of THF at $-40{ }^{\circ} \mathrm{C}$ for $72 \mathrm{~h}$; ${ }^{b}$ isolated yields; the ee values were determined by HPLC analysis on a chiral stationary phase; ${ }^{C}$ reactions were conducted at $-25^{\circ} \mathrm{C}$ for $32 \mathrm{~h}$. ride, chloride, or bromide occurred much slower than those with electron-donating groups. For examples, reactions of $\beta$-ketoesters $2 \mathbf{g}-\mathbf{h}$ and 20 required $32 \mathrm{~h}$ at $-25^{\circ} \mathrm{C}$ to convert completely to the desired products (Scheme 2, 3g-h and 3o). The effects of the steric hindrance of the ester group of $\beta$-ketoesters on the enantioselectivity of the reaction were not significant since the enantioselectivities increased from $88 \%$ ee to $92 \%$ ee when the ester group of $\beta$-ketoester was changed from the methyl group to the adamantyl group (Scheme 2, 3a-d). Thus, methyl esters of the six-membered ring $\beta$-ketoesters reacted with reagent 1c to form the corresponding trifluoromethylthiolated products in $94-98 \%$ ee (Scheme 2, 3i-o). As a comparison, organo-catalytic or transition-metal catalyzed asymmetric trifluoromethylthiolation of the six-membered ring $\beta$-ketoesters typically required the use of steric-bulky tert-butyl or adamantyl esters to achieve excellent enantioselectivity. ${ }^{7}$ The absolute configuration of compound $3 \mathbf{n}$ was established to be $R$ as determined by analysis of the X-ray diffraction data of its single crystal (Fig. 3). The configurations of the rest of the $\beta$-ketoesters were assigned based on the same mechanism assumption.

\section{Scope of the asymmetric trifluoromethylthiolation of oxindoles with reagent $1 \mathrm{c}$ or $1 \mathrm{~b}$}

Having established that compound 1c is an effective reagent for chirality transfer, we then tried to expand the scope of reagent 1c for asymmetric trifluoromethylthiolation reaction to other carbon-based nucleophiles. Oxindole represents one of the privileged structural units in many biologically active natural products and the development of highly enantioselective methods for trifluoromethylthiolation of oxindoles would be of great interest to medicinal chemists. As a matter of fact, three different organo-catalytic methods for asymmetric trifluoromethylthiolation of oxindoles have been reported recently. ${ }^{7 d-f}$ Interestingly, when the reaction of compound 1c and $\mathrm{N}$-methyl oxindole was conducted in THF at $-40{ }^{\circ} \mathrm{C}$ using 0.1 equivalent of $\mathrm{K}_{2} \mathrm{CO}_{3}$ as the base, moderate enantioselectivity of the desired product was observed. Instead, switching the base from $\mathrm{K}_{2} \mathrm{CO}_{3}$ to $\mathrm{Cs}_{2} \mathrm{CO}_{3}$ and the solvent from THF to $\mathrm{Et}_{2} \mathrm{O}$ led to a significant improvement of the enantioselectivity. As summarized in Scheme 3, a variety of 3-aryloxindoles reacted with compound 1c to give 3-trifluoromethylthio-3-aryloxindoles in excellent yields and with excellent enantioselectivities except for one case in which a cyanomethyl substituent was in the para-position of the 3-aryl group (Scheme 3, 4j). For this particular substrate, using compound

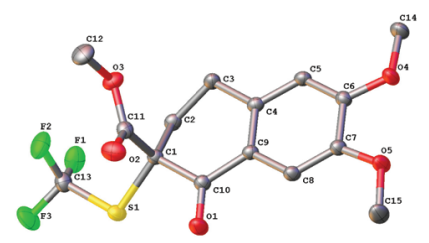

Fig. 3 ORTEP diagram of compound $3 n$. 


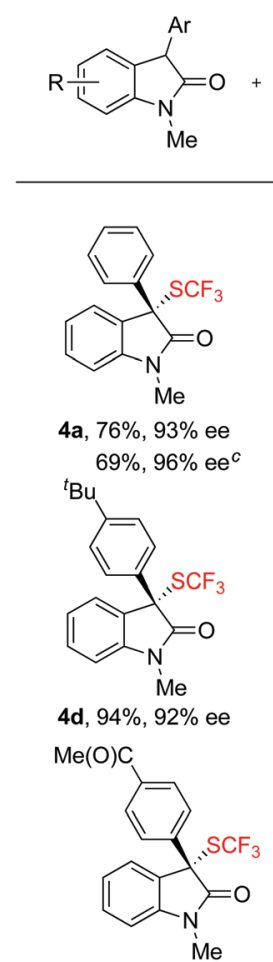

4g, $95 \%, 89 \%$ ee<smiles>CN1C(=O)[C@](c2ccccc2)(c2ccc(CC#N)cc2)c2ccccc21</smiles>

$\mathrm{Me}$

4 j, $87 \%, 57 \%$ ee $97 \%, 94 \% \mathrm{ee}^{c}$

$\mathrm{R}$<smiles></smiles>

$\mathrm{R}=\mathrm{Cl}, 4 \mathrm{~m}, 99 \%, 91 \% \mathrm{ee}^{\mathrm{c}}$ ${ }^{t} \mathrm{Bu}, 4 \mathbf{4 n}, 96 \%, 93 \%$ ee $^{\mathrm{C}}$

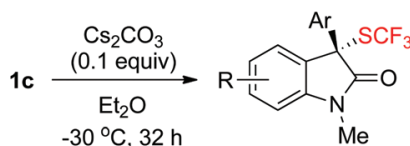

4a-p

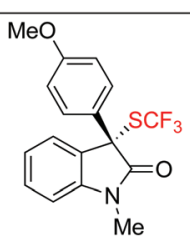

4b, $86 \%, 92 \%$ ee

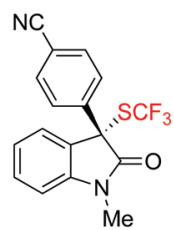

4 e, $97 \%, 94 \%$ ee<smiles>CN1C(=O)[C@](c2ccccc2)(c2ccc3ccccc3c2)c2ccccc21</smiles>

4h, $85 \%, 95 \%$ ee<smiles>CC(C)(C)OC(=O)N1C(=O)C(c2ccccc2)(c2ccccc2)c2ccccc21</smiles>

$\mathbf{4 k}, 98 \%, 93 \%$ ee $92 \%, 91 \% \mathrm{ee}^{c}$<smiles>CC(C)(C)OC(=O)N1C(=O)C(c2ccccc2)(c2ccccc2)c2c(F)cccc21</smiles>

$40,75 \%, 88 \% \mathrm{ee}^{c}$

$4 p, 76 \%, 79 \% \mathrm{ee}^{c}$

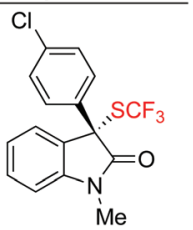

4c, $72 \%, 88 \%$ ee $95 \%, 93 \% \mathrm{ee}^{c}$ $\mathrm{MeO}_{2} \mathrm{C}$

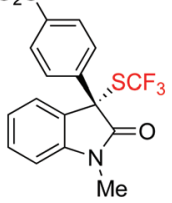

4f, $86 \%, 94 \%$ ee

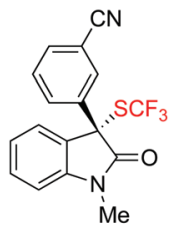

4i, $88 \%, 93 \%$ ee

$\mathrm{MeO}$

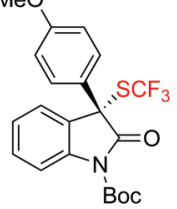

4I, $94 \%, 93 \% \mathrm{ee}^{\mathrm{c}}$<smiles>C/C=C\C(=C/C)[C@]1(C(F)(F)F)C(=O)Oc2ccccc21</smiles>

5a, $66 \%, 92 \% \mathrm{ee}^{\mathrm{c}}$

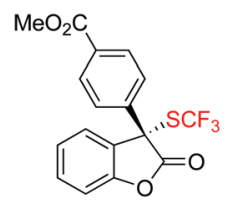

5d, $79 \%, 81 \% \mathrm{ee}^{d}$ mechanistic pathway.

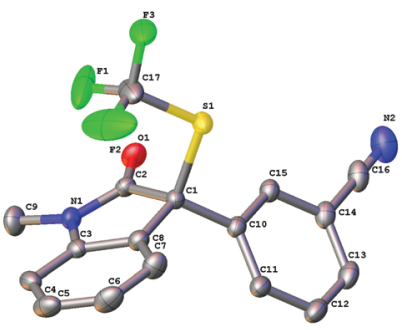

Fig. 4 ORTEP diagram of compound $4 \mathbf{i}$.

The absolute configuration of the optically active compound $4 \mathbf{i}$ was established to be $S$ as determined by analysis of the X-ray diffraction data of its single crystal (Fig. 4). The configurations of other oxindole derivatives were assigned based on the assumption that the reaction proceeded via a similar

\section{Scope of the asymmetric trifluoromethylthiolation of benzofuran-2 $(3 \mathrm{H})$-ones with reagent $1 \mathrm{c}$}

To further expand the scope of the asymmetric trifluoromethylthiolation of compound 1c, we studied the reactions of 2-aryl or 2-alkyl benzofuran-2(3H)-ones with compound 1c, as summarized in Scheme 4. In general, good to excel-

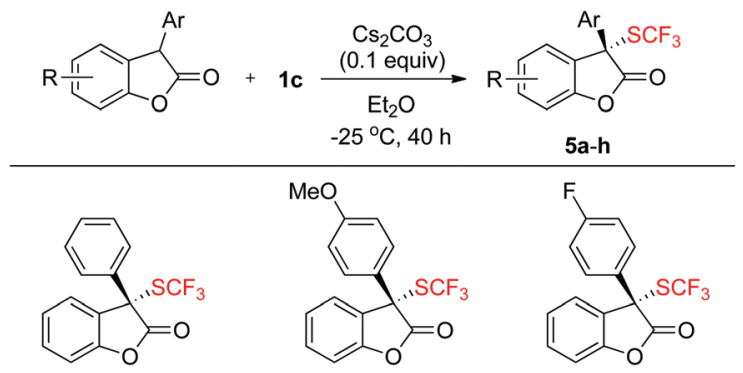

Scheme 3 Scope of the reactions of oxindoles with compound 1c or 1b. ${ }^{a, b}{ }^{a}$ Reaction conditions: oxindole $(0.50 \mathrm{mmol})$, reagent $1 \mathrm{c}$ $(0.55 \mathrm{mmol}), \mathrm{Cs}_{2} \mathrm{CO}_{3}(0.050 \mathrm{mmol})$ in $2.5 \mathrm{~mL}$ of $\mathrm{Et}_{2} \mathrm{O}$ at $-30{ }^{\circ} \mathrm{C}$ for $32 \mathrm{~h}$; ${ }^{b}$ isolated yields; the ee values were determined by HPLC analysis on a chiral stationary phase; ${ }^{c}$ reactions were conducted with compound $\mathbf{1 b}$.

1b as the chiral electrophilic trifluoromethylthiolating reagent greatly improved the enantioselectivity from $57 \%$ ee to $94 \%$ ee (Scheme 3, 4j). A few other examples also support that reactions of oxindoles with compound $\mathbf{1 b}$ occurred with higher enantioselectivities than those with compound 1c (Scheme 3, $\mathbf{4 a}, \mathbf{4 c}$ and $\mathbf{4 j}$ ). Because of the mild reaction conditions, various common functional groups such as the fluoride, chloride, bromide, cyano or ester group were tolerant. Nevertheless, reaction of 3-alkylated oxindoles with compound $\mathbf{1 b}$ occurred with moderate enantioselectivity (Scheme 3, 4p).

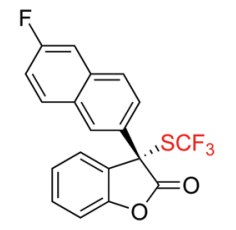

$5 \mathrm{~g}, 88 \%, 84 \%$ ee 5b, $81 \%, 89 \%$ ee

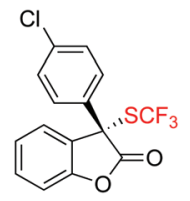

5 e, $88 \%, 86 \%$ ee 5c, $90 \%, 64 \%$ ee

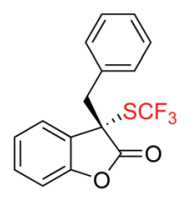

5f, $76 \%, 83 \%$ ee

Scheme 4 Scope of the reactions of benzofuran-2(3H)-ones with compound 1c. ${ }^{a, b}{ }^{a}$ Reaction conditions: benzofuran-2(3H)-ones $(0.5 \mathrm{mmol})$, reagent $1 \mathrm{c}(0.55 \mathrm{mmol}), \mathrm{Cs}_{2} \mathrm{CO}_{3}(0.05 \mathrm{mmol})$ in $\mathrm{Et}_{2} \mathrm{O}(2.5 \mathrm{~mL})$ at $-25^{\circ} \mathrm{C}$ for $40 \mathrm{~h}$; ${ }^{b}$ isolated yields; the ee values were determined by HPLC analysis on a chiral stationary phase; ${ }^{C}$ reactions were conducted at $-35{ }^{\circ} \mathrm{C}$ for $40 \mathrm{~h}$; ${ }^{d}$ reactions were conducted at $10{ }^{\circ} \mathrm{C}$ for $32 \mathrm{~h}$. 


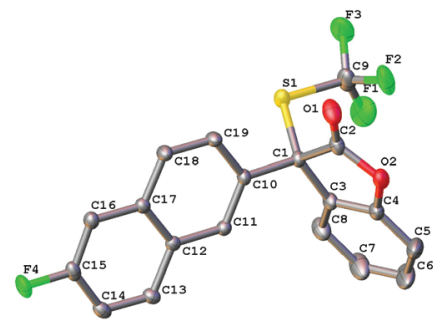

Fig. 5 ORTEP diagram of compound $\mathbf{5 g}$.

lent enantioselectivities (64-92\% ee) were achieved for the reactions of 2 -aryl or 2-alkyl benzofuran-2(3H)-ones with compound $1 \mathrm{c}$ when the reactions were conducted at $-25{ }^{\circ} \mathrm{C}$ for $40 \mathrm{~h}$ using $\mathrm{Cs}_{2} \mathrm{CO}_{3}$ as the base. Reaction of methyl 4-(2-oxo-2,3-dihydrobenzofuran-3-yl)benzoate with compound 1c was slow at $-25{ }^{\circ} \mathrm{C}$ but occurred to full conversion after $32 \mathrm{~h}$ at $10^{\circ} \mathrm{C}$ to give the corresponding product in $81 \%$ ee (Scheme 4, 5d). Reaction of alkyl substituted oxindoles occurred also smoothly to give the desired product in $76 \%$ yield and $83 \%$ ee (Scheme $4, \mathbf{5 f}$ ). Likewise, the absolute configuration of compound $\mathbf{5} \mathbf{g}$ was established to be $S$ as determined by analysis of the X-ray diffraction data of its single crystal (Fig. 5). The configurations of the rest of the lactones were assigned based on the same mechanism assumption.

\section{Experimental}

General procedure for the preparation of optically active electrophilic trifluoromethylthiolating reagent $1 \mathrm{a}$

To a solution of (1S)-(-)-2,10-camphorsultam (2.15 g, $10.0 \mathrm{mmol})$ in methanol $(15.0 \mathrm{~mL})$ and in a $50 \mathrm{~mL}$ roundbottom flask covered with aluminum foil was added tert-butylhypochlorite $(2.71 \mathrm{~g}, 25.0 \mathrm{mmol})$ under an argon atmosphere. The solution was then stirred at room temperature for $45 \mathrm{~min}$. The solution was evaporated under reduced pressure to give $(1 S)-(-)-N$-chloro-2,10-camphorsultam quantitatively, which was used directly without further purification. ${ }^{10}$

To an oven dried $500 \mathrm{~mL}$ Schlenk flask equipped with a stir bar was added dry (1S)-(-)- $N$-chloro-2,10-camphorsultam $(2.50 \mathrm{~g}, 10.0 \mathrm{mmol})$. The flask was fitted with a glass stopper and evacuated and refilled with argon three times. Dry MeCN $(30.0 \mathrm{~mL})$ was injected into the flask, then $\mathrm{AgSCF}_{3}(2.49 \mathrm{~g}$, $12.0 \mathrm{mmol}$ ) was added. The mixture was stirred vigorously at room temperature for $1 \mathrm{~h}$. The $\mathrm{CH}_{3} \mathrm{CN}$ was then evaporated under reduced pressure. And the residue was extracted with $\mathrm{CH}_{2} \mathrm{Cl}_{2}(3 \times 30.0 \mathrm{~mL})$. The solution was combined and dried over anhydrous $\mathrm{Na}_{2} \mathrm{SO}_{4}$. The solvent was evaporated under vacuum and the residue was purified by recrystallization from a solution of THF and petroleum ether to give $(1 S)-(-)-N$ trifluoromethylthio-2,10-camphorsultam 1a as a white solid (2.14 $\mathrm{g}, 68 \%$ yield).
General procedure for asymmetric trifluoromethylthiolation of $\boldsymbol{\beta}$-ketoesters

$\beta$-Ketoester 2a (95.1 mg, $0.500 \mathrm{mmol}, 1.0$ equiv.), potassium carbonate (7.90 mg, $0.0500 \mathrm{mmol}, 0.1$ equiv.) and reagent $1 \mathrm{c}$ (206 mg, $0.550 \mathrm{mmol}, 1.1$ equiv.) were added into a flamedried Schlenk tube. The tube was put into liquid nitrogen, and dry tetrahydrofuran $(2.5 \mathrm{~mL})$ was added under an argon atmosphere. The resulting solution was stirred at $-40{ }^{\circ} \mathrm{C}$ for $72 \mathrm{~h}$ (or $-25^{\circ} \mathrm{C}$ for $32 \mathrm{~h}$ ). After the reaction was complete as monitored by ${ }^{19} \mathrm{~F}$ NMR spectroscopy, the reaction was quenched by addition of $\mathrm{HCl}(2.0 \mathrm{M})$. The mixture was extracted with $\mathrm{Et}_{2} \mathrm{O}$ $(3 \times 10.0 \mathrm{~mL})$. The organic phase was separated and dried over anhydrous $\mathrm{Na}_{2} \mathrm{SO}_{4}$. After filtration, the solvent was removed under vacuum. The residue was purified by flash chromatography to give the trifluoromethylthiolated product $\mathbf{3 a}$ $(R)$-methyl-1-oxo-2-((trifluoromethyl)thio)-2,3-dihydro- $1 H$-indene2-carboxylate 3a as a white solid (136 mg, 94\% yield). HPLC: (IE-3 $(0.46 \times 25 \mathrm{~cm}, 3 \mu \mathrm{m})$, hexane $/{ }^{\mathrm{i}} \mathrm{PrOH}=97 / 3,0.7 \mathrm{~mL} \mathrm{~min}{ }^{-1}$, $214 \mathrm{~nm}), t_{\mathrm{R}}$ (major) $=12.13 \mathrm{~min}, t_{\mathrm{S}}($ minor $)=12.93 \mathrm{~min}$ (88\% ee); $[\alpha]_{\mathrm{D}}^{25}=-99.2\left(c=0.110, \mathrm{CHCl}_{3}, 88 \%\right.$ ee $)$.

General procedure for asymmetric trifluoromethylthiolation of oxindoles with reagent $1 \mathrm{c}$

Oxindole (112 mg, $0.500 \mathrm{mmol}, 1.0$ equiv.), cesium carbonate (16.3 mg, $0.0500 \mathrm{mmol}, 0.1$ equiv.) and compound 1c (206 mg, $0.550 \mathrm{mmol}, 1.1$ equiv.) were added into a flame-dried Schlenk tube. The tube was put into liquid nitrogen. Dry ethyl ether $(2.5 \mathrm{~mL})$ was added under an argon atmosphere. The resulting solution was stirred at $-30^{\circ} \mathrm{C}$ for $32 \mathrm{~h}$. After the reaction was complete as monitored by ${ }^{19} \mathrm{~F}$ NMR spectroscopy, the reaction was quenched with $\mathrm{HCl}(2.0 \mathrm{M})$. The mixture was extracted with $\mathrm{Et}_{2} \mathrm{O}(3 \times 10.0 \mathrm{~mL})$. The combined organic phase was separated and dried over anhydrous $\mathrm{Na}_{2} \mathrm{SO}_{4}$. After filtration, the solvent was removed under vacuum. The residue was purified by flash chromatography to give $(S)$-1-methyl-3-phenyl-3-((trifluoromethyl)thio)indolin-2-one $\mathbf{4 a}$ as a white solid (122 mg, $76 \%$ yield $)$. HPLC: $\left(\right.$ AD-H $(0.46 \times 25 \mathrm{~cm}, 5 \mu \mathrm{m})$, hexane $/{ }^{\mathrm{i}} \mathrm{PrOH}=$ $95 / 5,0.7 \mathrm{~mL} \mathrm{~min}^{-1}, 214 \mathrm{~nm}$ ), $t_{\mathrm{S}}$ (major) $=9.83 \mathrm{~min}, t_{\mathrm{R}}$ (minor) $=9.04 \min (93 \%$ ee $) ;[\alpha]_{\mathrm{D}}^{25}=+102.4\left(c=0.140, \mathrm{CHCl}_{3}, 93 \%\right.$ ee $)$.

General procedure for asymmetric trifluoromethylthiolation of benzofuranones with compound $1 \mathrm{c}$

Benzofuranone (105 mg, $0.500 \mathrm{mmol}, 1.0$ equiv.), cesium carbonate (16.3 mg, $0.0500 \mathrm{mmol}, 0.1$ equiv.) and compound $1 \mathrm{c}$ (206 mg, $0.550 \mathrm{mmol}, 1.1$ equiv.) were added into a flamedried Schlenk tube. The tube was put into liquid nitrogen. Dry ethyl ether $(2.5 \mathrm{~mL})$ was added under an argon atmosphere. The resulting solution was stirred at $-25{ }^{\circ} \mathrm{C}$ for $40 \mathrm{~h}$. After the reaction was complete as monitored by ${ }^{19} \mathrm{~F}$ NMR spectroscopy, the reaction was quenched with $\mathrm{HCl}(2.0 \mathrm{M})$. The mixture was extracted using $\mathrm{Et}_{2} \mathrm{O}(3 \times 10.0 \mathrm{~mL})$. The organic phase was separated and dried over anhydrous $\mathrm{Na}_{2} \mathrm{SO}_{4}$. After filtration, the solvent was removed under vacuum. The residue was purified by flash chromatography to give $(S)$-3-phenyl-3-((trifluoromethyl)thio)benzofuran-2(3H)-one $\mathbf{5 a}$ as a colorless oil 
(102 mg, 66\% yield). HPLC: (IE-3 $(0.46 \times 25 \mathrm{~cm}, 3 \mu \mathrm{m})$,

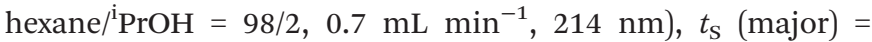
$8.25 \mathrm{~min}, t_{\mathrm{R}}$ (minor) $=7.93 \min (92 \%$ ee $) ;[\alpha]_{\mathrm{D}}^{25}=+92.9(c=$ $0.050, \mathrm{CHCl}_{3}, 92 \%$ ee).

\section{Conclusions}

In summary, a family of easily scalable, shelf-stable, optically pure reagents $(1 S)-(-)-N$-trifluoromethylthio-2,10-camphorsultam 1a-c was successfully developed. Among them, compound 1c was shown to be an efficient reagent that is capable of transferring its chirality to other prochiral nucleophiles, as demonstrated by its reactions with $\beta$-ketoesters, oxindoles and benzofuranones with good to excellent enantioselectivities. The studies for further applications of reagent 1c toward the construction of a stereogenic tertiary carbon center bearing a trifluoromethylthio group are undergoing currently in our laboratory.

\section{Acknowledgements}

The authors gratefully acknowledge the financial support from the National Natural Science Foundation of China (21625206, 21632009, 21372247, 21572258, and 21421002) and the Strategic Priority Research Program of the Chinese Academy of Sciences (XDB20000000).

\section{Notes and references}

1 (a) R. Filler, Biomedical Aspests of Fluorine Chemistry, Kodansha, Tokyo, 1982; (b) S. Purser, P. R. Moore, S. Swallow and V. Gouverneur, Chem. Soc. Rev., 2008, 37, 320; (c) W. K. Hagmann, J. Med. Chem., 2008, 51, 4359; (d) N. A. Meanwell, J. Med. Chem., 2011, 54, 2529; (e) J. Wang, M. Sánchez-Roselló, J. Aceña, C. Pozo, A. E. Sorochinsky, S. Fustero, V. A. Soloshonok and H. Liu, Chem. Rev., 2014, 114, 2432.

2 (a) A. Leo, C. Hansch and D. Elkins, Chem. Rev., 1971, 71, 525; (b) C. Hansch, A. Leo and R. W. Taft, Chem. Rev., 1991, 91, 165; (c) G. Landelle, A. Panossian and F. R. Leroux, Curr. Top. Med. Chem., 2014, 14, 941.

3 (a) F. Leroux, P. Jeschke and M. Schlosser, Chem. Rev., 2005, 105, 827; (b) B. Manteau, S. Pazenok, J.-P. Vors and F. R. Leroux, J. Fluorine Chem., 2010, 131, 140; (c) V. N. Boiko, Beilstein J. Org. Chem., 2010, 6, 880; (d) G. Landelle, A. Panossian, S. Pazenok, J.-P. Vors and F. R. Leroux, Beilstein J. Org. Chem., 2013, 9, 2476; (e) T. Liang, C. N. Neumann and T. Ritter, Angew. Chem., Int. Ed., 2013, 52, 8214; (f) X.-X. Shao, C.-F. Xu, L. Lu and Q. Shen, Acc. Chem. Res., 2015, 48, 1227; (g) X.-H. Xu, K. Matsuzaki and N. Shibata, Chem. Rev., 2015, 115, 731; (h) C.-F. Ni, M.-Y. Hu and J.-B. Hu, Chem. Rev., 2015, 115, 765 .
4 Selected examples for transition metal-catalyzed or -mediated trifluoromethylthiolation methods: (a) G. Teverovskiy, D. S. Surry and S. L. Buchwald, Angew. Chem., Int. Ed., 2011, 50, 7312; (b) C. P. Zhang and D. A. Vicic, J. Am. Chem. Soc., 2012, 134, 183; (c) C. Chen, Y. Xie, L.-L. Chu, R.-W. Wang, X.-G. Zhang and F.-L. Qing, Angew. Chem., Int. Ed., 2012, 51, 2492; (d) Z. Weng, W. He, C. Chen, R. Lee, D. Dan, Z. Lai, D. Kong, Y. Yuan and K.-W. Huang, Angew. Chem., Int. Ed., 2013, 52, 1548; (e) G. Danoun, B. Bayarmagnai, M. F. Grünberg and L. J. Gooßen, Chem. Sci., 2014, 5, 1312; (f) R. Pluta, P. Nikolaienko and M. Rueping, Angew. Chem., Int. Ed., 2014, 53, 150; ( $g$ ) K. Kang, C.-F. Xu and Q. Shen, Org. Chem. Front., 2014, 1, 294; (h) W.-Y. Yin, Z.-F. Wang and Y. Huang, Adv. Synth. Catal., 2014, 356, 2998; (i) J. Sheng, S.-Y. Li and J. Wu, Chem. Commun., 2014, 50, 578; (j) H.-Y. Xiong, T. Besset, D. Cahard and X. Pannecoucke, J. Org. Chem., 2015, 80, 4204; (k) G. Yin, I. Kalvet, U. Englert and F. Schoenebeck, J. Am. Chem. Soc., 2015, 137, 4164; (l) G. Yin, I. Kalvet and F. Schoenebeck, Angew. Chem., Int. Ed., 2015, 54, 6809.

5 Reviews for electrophilic trifluoromethylthiolating reagents: (a) F. Toulgoat, S. Alazet and T. Billard, Eur. J. Org. Chem., 2014, 2415; (b) H. Chachignon and D. Cahard, Chin. J. Org. Chem., 2016, 34, 445; (c) S. Barata-Vallejo, S. Bonesi and A. Postigo, Org. Biomol. Chem., 2016, 14, 7150.

6 Selected examples for trifluoromethylthiolation with electrophilic trifluoromethylthiolating reagents: (a) A. Ferry, T. Billard, B. R. Langlois and E. Bacqué, J. Org. Chem., 2008, 73, 9362; (b) S. Alazet, L. Zimmer and T. Billard, J. Fluorine Chem., 2015, 171, 78; (c) Y.-D. Yang, A. Azuma, E. Tokunaga, M. Yamasaki, M. Shiro and N. Shibata, J. Am. Chem. Soc., 2013, 135, 8782; (d) X.-X. Shao, X.-Q. Wang, T. Yang, L. Lu and Q. Shen, Angew. Chem., Int. Ed., 2013, 52, 3457; (e) E. V. Vinogradova, P. Müller and S. L. Buchwald, Angew. Chem., Int. Ed., 2014, 53, 3125; (f) S. Munavalli, D. K. Rohrbaugh, D. I. Rossman, F. J. Berg, G. W. Wagner and H. D. Durst, Synth. Commun., 2000, 30, 2847; $(g)$ C. Xu, B. Ma and Q. Shen, Angew. Chem., Int. Ed., 2014, 53, 9316; (h) P.-P. Zhang, M. Li, X.-S. Xue, C.-F. Xu, Q.-C. Zhao, Y.-F. Liu, H.-Y. Wang, Y.-L. Guo, L. Lu and Q. Shen, J. Org. Chem., 2016, 81, 7486.

7 (a) T. Bootwicha, X. Liu, R. Pluta, I. Atodiresei and M. Rueping, Angew. Chem., Int. Ed., 2013, 52, 12856; (b) X.-Q. Wang, T. Yang, X.-L. Cheng and Q. Shen, Angew. Chem., Int. Ed., 2013, 52, 12860; (c) Q.-H. Deng, C. Rettenmeier, H. Wadepohl and L. H. Gade, Chem. - Eur. J., 2014, 20, 93; (d) X.-L. Zhu, J.-H. Xu, D.-J. Cheng, L.-J. Zhao, X.-Y. Liu and B. Tan, Org. Lett., 2014, 16, 2192; (e) M. Rueping, X. Liu, T. Bootwicha, R. Pluta and C. Merkens, Chem. Commun., 2014, 50, 2508; $(f)$ T. Yang, Q. Shen and L. Lu, Chin. J. Chem., 2014, 32, 678; (g) X. Liu, R. An, X.-L. Zhang, J. Luo and X. D. Zhao, Angew. Chem., Int. Ed., 2016, 55, 5846.

8 (a) I. Farnadez and N. Khiar, Chem. Rev., 2003, 103, 3651; (b) J. M. Brunel, Chem. Rev., 2007, 107, PR1. 
9 Review about camphorsultam-based optically pure reagents: (a) M. M. Heravi and V. Zadsirjan, Tetrahedron: Asymmetry, 2014, 25, 1061. Reports on camphorsultambased optically pure fluorinating reagents: (b) E. Differding, G. W. Ruegg and R. W. Lang, Tetrahedron Lett., 1991, 32, 1779; (c) F. A. Davis, P. Zhou, C. K. Murphy, G. Sundarababu, H. Qi, W. Han, R. M. Przeslawski,
B.-C. Chen and P. J. Carroll, J. Org. Chem., 1998, 63, 2273; (d) Y. Takeuchi, Z. Liu, A. Satoh, T. Shiragami and N. Shibata, Chem. Pharm. Bull., 1999, 47, 1730; (e) Z.-P. Liu, N. Shibata and Y. Takeuchi, J. Org. Chem., $2000,65,7583$.

10 L. Duhamel, G. Ple and P. Angibaud, Synth. Commun., 1993, 23, 2423. 